\title{
Entrepreneurship in Agricultural Sciences - Challenges and Strategies
}

\author{
C. Muralidharan*, R. Senthil Kumar, R. Pangayar Selvi and R. Gangai Selvi \\ Department of Social Sciences, Agricultural College and Research Institute, \\ Killikulam, Tuticorin District, India \\ *Corresponding author
}

\section{A B S T R A C T}

\begin{tabular}{l} 
K e y w o r d s \\
Entrepreneurship, \\
Agricultural \\
Sciences, \\
Challenges and \\
Strategies \\
\hline Article Info \\
\hline $\begin{array}{l}\text { Accepted: } \\
12 \text { October } 2020 \\
\text { Available Online: } \\
10 \text { November } 2020\end{array}$ \\
\hline
\end{tabular}

Entrepreneurs create lot of job opportunities, economic development and wealth of the nation by paying taxes. During this process of economic development, they face lot of challenges, uncertainty and unavoidable risks. Further, research reports revealed that success percentage of entrepreneurs and start ups in India were minimum (i.e.) ten percent. It was predicted that huge opportunities exists in case of agribusiness ventures. However, there exist gaps and challenges in case of entrepreneurship in agribusiness. In order to bridge this gap, the research study was conducted to identify the challenges and possible strategies. In this research study, purposive sampling method was adopted to find better results. About 50 numbers of entrepreneurs enrolled as member in agribusiness incubators were selected for this study. Primary data were collected based on the interaction with the entrepreneurs through focused group discussion and personal interview method. Research results revealed that difficulty in obtaining credit from financial institutions (72.16 percent) obtained first rank followed by faced lot of hurdles towards procedural compliance (67.68 percent), gap in market linkages and target market (59.28 percent), lack of moral support from family members and pressure to seek job for work and social stigma (54.28 per cnet), facing lot of challenges in technology commercialization (49.64 percent), lack of access to critical resources viz., skilled manpower (43 percent), lack of previous experience (31.28 percent) and lack of networking and mentoring (22.20) respectively. Based on the challenges, following suggestions were provided by the respondents viz., establishment of business incubators in all districts, proper market linkage and value chain, financial assistance and tailor made capacity building programmes suitable for entrepreneurs in the domain of agribusiness.

\section{Introduction}

India is blessed with varied agro climatic zones and produces food to one sixth population of the world and aiming to attain the target of four per cent annual growth consistently. In order to achieve above growth, there is an urgent need that more number of agripreneurs and start ups should invest in agriculture. However, macro business environment supporting the growth of startup is not conducive to the new agripreneur. Research reports revealed that success percentage of entrepreneurs and start ups in India were minimum (i.e.) ten percent (Nell, 2015). This was supported with the 
World Bank report 2020, analyzed with various indictors revealed that India's rank for "ease of doing business" is $63^{\text {rd }}$ place out of 190 countries in the world in the year 2019 . Further, India scored $69^{\text {th }}$ place in the Global Entrepreneurship Index 2019. The profile of India's entrepreneurial ecosystem is considerably less developed and more uneven than those of countries like USA and Japan.

The biggest bottlenecks for the India's entrepreneurial ecosystem are lack of opportunity startup, internationalization, less number of startup skills, and minimum product innovation (GEDI, 2016). Innovation is one of the major attributes of Entrepreneurship that could enhance the performance of any business. As per Global Innovation Index 2019, reported that India is ranked with $52^{\text {nd }}$ place out of 190 countries in the world. It is supported that 10,669 patents were filed in India form the year 2011 to 2015, compared with China $(8,01,135)$, United states $(2,85,096)$, Japan $(2,65,959)$, and South Korea $(1,64,073)$ respectively. There was huge gap exists between India and above countries. However, developed countries are predicted to face a shortfall of 57 million semi skilled manpower in the year 2022 whereas; India is expected to have a surplus of 47 million semi skilled manpower. In contrast to above, National Policy for Skill Development and Entrepreneurship, 2015 reported that there will be skill gap of 109.73 million in 24 key sectors by the year 2022 in India.

In order to bridge the above gap, Government of India (GOI) had implemented various innovation based entrepreneurial promotion schemes viz., Make in India, Startup India, Standup India, Digital India, Science and technology Entrepreneurship Park(STEP), Technology Business Incubator(TBI), BIRAC sponsored University Innovation Cluster (UIC) and NITI Ayog sponsored Atal
Innovation Mission (AIM), PMEGP, UYEGP and subsidy linked agricultural projects. Majority of the agricultural projects and activities are focused towards rural areas because of the availability of natural resources, cheap labour and capital. In rural areas, almost 50 per cent of the population belonged to youth and greater parts of them were unemployed (National Youth Policy 2014). Entrepreneurship rates vary by age group and with the highest rates of entrepreneurial activities are occurring in the 25-34 age groups.

Majority of the entrepreneurial activities are occurred at the age group between 35 and 44 (Table 2). Hence, startups are liable to be adult and middle age group. With regards to the employment scenario in rural areas, the proportion of persons engaged in agriculture domain in comparison with other domains indicated suffered maximum extent due to risk and uncertainty. It was reported that agriculture remains the main occupation in rural areas but the proportion of population depending on agriculture is declining over the years (Sinha, 2013). Migration of rural people towards urban, offering better job prospects in urban and providing employment opportunities other than agriculture are different challenges mitigating the agricultural growth in rural areas.

Apart from above challenges, there are huge opportunities still exists in agriculture domain and it is possible that agriculturists can become an agripreneur. With this back ground, there is a need and greater importance to be given for the development of agripreneurship in rural areas. This paper deals with the challenges faced by entrepreneurs engaged in agriculture domain, opportunities and strategies that could enhance the development of agripreneurship in rural areas were discussed. 
Research design describes about the method of tools and techniques employed in the research study. Purposive sampling method was adopted for this study because it focused mainly on entrepreneurs in the domain of agribusiness. About 50 numbers of entrepreneurs enrolled as member in agribusiness incubators were selected for this study. As this study was sectoral and specific in nature and hence sample size was small and purposive. Primary data were collected based on the interaction with the entrepreneurs through focused group discussion method followed by personal interview. The statistical tools employed for this study was Gareett ranking method and percentage analysis in order to arrive better results. Respondents were informed to discuss in group, rank the challenges faced by them and possible strategies to enhance entrepreneurship through questionnaire.

\section{Challenges faced by entrepreneurs}

Entrepreneurs are job providers and create lot of employment opportunities and generate revenue to the government in the form of taxes. They are risk takers and faces lot of challenges in the normal course. Challenges faced by entrepreneurs in the domain of agriculture are listed below in Table 1.

From the above table 1, it is observed that difficulty in obtaining credit from financial institutions (72.16 percent) obtained first rank followed by faced lot of hurdles towards procedural compliance (67.68 percent), gap in market linkages and target market (59.28 percent), lack of moral support from family members and pressure to seek job for work and social stigma (54.28 per cet), facing lot of challenges in technology commercialization (49.64 percent), lack of access to critical resources viz., skilled manpower (43 percent), lack of previous experience (31.28 percent) and lack of networking and mentoring (22.20) respectively. It is in support Kumari and Kaushik (2010) revealed that the problem faced by rural entrepreneurs were financial crises, raw material selection, collection and storage and marketing problems. Based on the challenges, following strategies were suggested by entrepreneurs in the domain of agriculture

\section{Strategies to boost the entrepreneurial ecosystem}

As an outcome of the research study, respondents suggested the following strategies and policies for promoting entrepreneurship in the domain of agriculture.

\section{Need for business incubators}

Business incubators are established with the objective of enhancing the business acumen among startups and budding entrepreneurs. It nurtures, grooms, promotes, develops and provides hand holding services to startups and also transforming the business ventures into innovative one and improving the socio economic conditions of all stakeholders in the business ecosystem. Services availed by agripreneurs through business incubators are handholding support, business incubation, business plan, bankable project preparation, patenting services, technology licensing, commercialization, facilitating incubates to obtain financial services, grant support under MSME schemes, market linkages, networking, branding, analytical and consultancy services. Infrastructural facilities are provided at subsidized rate, Incubation of start-up companies, business promotion, technology support and handholding services, technology commercialization, financial support from banks and MSME, technical consultancy services, market linkages, interface meets, training programmes on capacity building, patent services for innovative process \& products, sales 
promotional activities, access to training, seminar halls and laboratories, quality testing of samples and certification services, Apart from these, ideathon competitions, boot camps, hackathon, interactive workshops, conclaves, interface meet, pitching competitions and webinars are regularly conducted for the benefit of agripreneurs.

Respondents revealed that startups are executing unique business models and prefer innovative hybrid models of financing viz., angel funds, venture capital, equity funds and crowd funding opportunities rather than traditional bank loans. In order to avail these funding opportunities, business incubators need to be established and should handhold entrepreneurs. Thus it could play a crucial role in promoting entrepreneurs.

\section{Market linkages}

Assisting the startups for branding their products, Develop user friendly mobile app exclusively for rural entrepreneurship for their domain skill specialization, Network the skilled rural agriculture with other incubators and incubatee members and explore the possibility and facilitate him to become an entrepreneur.

\section{Financial assistance}

Respondents suggested that financial assistance need to be provided to newly formed "Entrepreneurial and skill clubs" in rural areas. Further, maintenance cost may be provided for the club for the initial period of three years. Special privileges and tailor made exclusive rural packages in the form of financial assistance should be provided to rural agriculturists in all Government schemes. Seed money in the form of venture capital assistance may be provided to the inventors in rural areas.
Tweaking the existing policies and programmes

During the focused group discussion, it was revealed that region and location specific skill mapping can be prepared in order to develop the skill competency in rural areas. Public Procurement Policy (PPP) for Micro and Small Enterprises (MSE), minimum 20 per cent share out of the total procurement by Central Government Ministries/ Departments / Public Sector Undertakings are to be made from MSME. It was suggested to establish common infrastructural facilities (High cost machineries and equipments, testing and laboratory facilities etc, ) on a cluster basis in rural areas. Separate online web portal need to be created exclusively for the rural entrepreneurs and contact phone/ mobile numbers of skilled youth trained in the specialized domain need to be registered in this portal. Exposure visits need to be arranged for rural entrepreneurs to incubators and startup units.

\section{Capacity building programmes}

Respondents revealed that one week Summer / Winter Camps on "Entrepreneurial Adventures for Youth in the age group of 1524 years" may be conducted at the state level. The purpose is to achieve the developmental path in the life of a youth can be supplemented with effective guiding and mentoring. Mobile training centres and in house capacity building programmes need to be conducted at regular interval.

Agro based Vocational Education and Training (VET) institutes could be established in rural areas. Empanelment of resource persons need to be formed to assist the Agripreneurs to prepare the Detailed Project Reports (DPRs), preparation of bankable projects and availing subsidies in banks. 
Table.1 Challenges faced by entrepreneurs in the domain of agriculture $(n=50)$

\begin{tabular}{|c|l|c|c|}
\hline S. No & \multicolumn{1}{|c|}{ Particulars } & $\begin{array}{l}\text { Mean } \\
\text { Score }\end{array}$ & Rank \\
\hline $\mathbf{1}$ & Difficulty in obtaining credit from Financial institutions & 72.16 & I \\
\hline $\mathbf{2}$ & Faced lot of hurdles towards procedural compliance & 67.68 & II \\
\hline $\mathbf{3}$ & Gap in market linkages and target market & 59.28 & III \\
\hline $\mathbf{4}$ & $\begin{array}{l}\text { Lack of moral support from family members and pressure to seek } \\
\text { job for work and social stigma }\end{array}$ & 54.28 & IV \\
\hline $\mathbf{5}$ & Facing lot of challenges in technology commercialization & 49.64 & V \\
\hline $\mathbf{6}$ & Lack of access to critical resources viz., skilled manpower & 43.00 & VI \\
\hline $\mathbf{7}$ & Lack of previous experience & 31.28 & VII \\
\hline $\mathbf{8}$ & Lack of networking and mentoring & 22.20 & VIII \\
\hline
\end{tabular}

Table.2 Total Entrepreneurial Activities (TEA) across age groups (2007-14)

\begin{tabular}{|c|c|c|c|c|c|}
\hline \multirow{2}{*}{ Year } & \multicolumn{5}{|c|}{ Age category } \\
\cline { 2 - 6 } & $\mathbf{1 8 - 2 4}$ & $\mathbf{2 5 - 3 4}$ & $\mathbf{3 5 - 4 4}$ & $\mathbf{4 5 - 5 4}$ & $\mathbf{5 5 - 6 4}$ \\
\hline $\mathbf{2 0 0 7}$ & 7.08 & 11.44 & 10.12 & 8.21 & 4.69 \\
\hline $\mathbf{2 0 0 8}$ & 7.56 & 12.62 & 10.47 & 8.39 & 5.25 \\
\hline $\mathbf{2 0 0 9}$ & 6.95 & 12.25 & 10.22 & 8.11 & 5.44 \\
\hline $\mathbf{2 0 1 0}$ & 6.42 & 11.02 & 10.06 & 8.35 & 4.72 \\
\hline $\mathbf{2 0 1 1}$ & 8.29 & 13.10 & 12.65 & 10.20 & 7.00 \\
\hline $\mathbf{2 0 1 2}$ & 8.19 & 12.86 & 11.20 & 9.11 & 5.79 \\
\hline $\mathbf{2 0 1 3}$ & 8.66 & 13.13 & 12.15 & 9.31 & 6.08 \\
\hline $\mathbf{2 0 1 4}$ & 8.74 & 13.65 & 12.43 & 9.57 & 6.36 \\
\hline Average & $\mathbf{7 . 7 4}$ & $\mathbf{1 2 . 5 1}$ & $\mathbf{1 1 . 1 6}$ & $\mathbf{8 . 9 1}$ & $\mathbf{5 . 6 7}$ \\
\hline \% point change (2007-14) & $\mathbf{1 . 6 6}$ & $\mathbf{2 . 2 2}$ & $\mathbf{2 . 3 2}$ & $\mathbf{1 . 3 6}$ & $\mathbf{1 . 6 7}$ \\
\hline
\end{tabular}

Source: GEDI, 2016

Respondents suggested that awareness can be created among entrepreneurs with respect to government sponsored schemes viz., Prime Ministers Employment Generation Programme (PMEGP), Rural Entrepreneurship Development Programme (REDP), Rural Development and Self Employment Training Institute (RUDSETI), Deen Dayal Upadhyaya Grameen Kaushalya Yojana (DDU-GKY), Pradhan Mantri Mudra Yojana (PMMY) and Udyamita. A centrally sponsored project creates the enabling ecosystem for entrepreneurship development through entrepreneurial education, training and advocacy.

In order to conclude, it was suggested that there is a need to establish the holistic entrepreneurial eco system to promote entrepreneurship in agriculture domain (i.e) business incubators at district level at the initial stage and later at the block level following the hub and spokes model. Universities providing technology will act as nodal centre and hubs at district and block level will provide the accessibility of the 
University technologies to the needy agripreneurs. Better market linkage for achieving higher price, Market survey/ marketing assistance. Hand holding facilities, Business planning and training, organizing management/ technical assistance, assistance in obtaining statutory approvals, Information dissemination on product ideas/technologies, syndicating finances, arranging legal and IPR services, using infrastructural facilities of the Host Institute (HI) at nominal charges, work space for a limited period and common facilities of Business incubation such as communication, laboratories, conference rooms and computers,

\section{References}

Kumari, Sujata, Kaushik, V and Lodha, N (2010). Problems Faced by Rural Women Entrepreneurs of Rajasthan. Studies on Home and Community Sciences, 04(2): 115-119

Nell Patel. (2015). Retrieved on January, 6 from http://www.forbes.com/sites/ neil patel/2015/01/16 /90- of-startups-willfail-heres-what-you-need-to- knowabout-the-10/\#49127ac155e1/

https://thegedi.org/

\section{How to cite this article:}

Muralidharan, C., R. Senthil Kumar, R. Pangayar Selvi and Gangai Selvi, R. 2020. Entrepreneurship in Agricultural Sciences-Challenges and Strategies. Int.J.Curr.Microbiol.App.Sci. 9(11): 1644-1649. doi: https://doi.org/10.20546/ijcmas.2020.911.196 